\title{
Extratropical cyclones in a warmer, moister climate: a recent Atlantic analogue
}

Article

Published Version

Li, M., Woollings, T., Hodges, K. and Masato, G. (2014)

Extratropical cyclones in a warmer, moister climate: a recent Atlantic analogue. Geophysical Research Letters, 41 (23). pp.

8594-8601. ISSN 0094-8276 doi:

https://doi.org/10.1002/2014GL062186 Available at https://centaur.reading.ac.uk/41490/

It is advisable to refer to the publisher's version if you intend to cite from the work. See Guidance on citing.

Published version at: http://dx.doi.org/10.1002/2014GL062186

To link to this article DOI: http://dx.doi.org/10.1002/2014GL062186

Publisher: American Geophysical Union

All outputs in CentAUR are protected by Intellectual Property Rights law, including copyright law. Copyright and IPR is retained by the creators or other copyright holders. Terms and conditions for use of this material are defined in the End User Agreement.

\section{www.reading.ac.uk/centaur}

\section{CentAUR}

Central Archive at the University of Reading 
Reading's research outputs online 


\section{Geophysical Research Letters}

\author{
RESEARCH LETTER \\ 10.1002/2014GL062186 \\ Key Points: \\ - Recent warm AMV periods are partial \\ analogues of future warming \\ - In warm periods, cyclone \\ precipitation increases but they \\ do not intensify \\ - Changes in storm intensity may be \\ different at high resolution
}

\section{Supporting Information:}

- Readme

- Table S1

\section{Correspondence to:}

T. Woollings,

woollings@atm.ox.ac.uk

\section{Citation:}

Li, M., T. Woollings, K. Hodges, and

G. Masato (2014), Extratropical

cyclones in a warmer, moister cli-

mate: A recent Atlantic analogue, Geophys. Res. Lett., 41, 8594-8601, doi:10.1002/2014GL062186.

Received 13 OCT 2014 Accepted 17 NOV 2014 Accepted article online 19 NOV 2014 Published online 9 DEC 2014

\section{Extratropical cyclones in a warmer, moister climate: A recent Atlantic analogue}

\author{
Muxingzi Li' ${ }^{1}$ Tim Woollings ${ }^{1}$, Kevin Hodges ${ }^{2}$, and Giacomo Masato ${ }^{2}$ \\ ${ }^{1}$ Atmospheric, Oceanic and Planetary Physics, University of Oxford, Oxford, UK, ${ }^{2}$ Department of Meteorology, University \\ of Reading, Reading, UK
}

Abstract Current climate model projections do not exhibit a large change in the intensity of extratropical cyclones. However, there are concerns that current models represent moist processes poorly, and this provides motivation for investigating observational evidence for how cyclones behave in warmer climates. In the North Atlantic in particular, recent decades provide a clear contrast between warm and cold climates due to Atlantic Multidecadal Variability. In this paper we investigate these periods as analogues which may provide a guide to future cyclone behavior. While temperature and moisture rise in recent warm periods as in the projections, differences in energetics and temperature gradients imply that these periods are only partial analogues. The main result from current reanalyses is that while increased cyclone-associated precipitation is seen in the recent warm periods, there is no robust evidence of an increase in cyclone intensity by other measures, such as maximum wind speed or vorticity. A set of low- and high-resolution model simulations are also studied, suggesting that changes in cyclone intensity may be different in higher-resolution reanalyses.

\section{Introduction}

Considerable uncertainty remains over how the extratropical storm tracks will respond to climate change. This is partly because projected shifts of the storm tracks reflect the net effect of several competing factors, such as the changing temperature gradients at upper and lower levels [Harvey et al., 2013]. Another key factor is the increase in specific humidity as the atmosphere warms, and this itself is likely to have two competing effects on the storm track.

First, it is well established that the latent heating arising from moist condensation often acts to strengthen cyclones via the resulting ascent and diabatic potential vorticity anomalies [e.g., Gutowski et al., 1992]. This has led to suggestions that cyclones could intensify in a warmer, moister climate [Willison et al., 2013].

Second, the increase in moisture has a competing effect via the energetics of the large-scale circulation. Midlatitude cyclones are predominantly driven by baroclinic instability, reflecting the need for the atmosphere to transport heat poleward. Increased moisture content leads to increased poleward transport of moisture and hence latent heat [Hwang and Frierson, 2010]. The result is an effective increase in the efficiency of poleward heat transport so that weaker eddy kinetic energy is required to transport the same amount of heat [Manabe and Bryan, 1985; Boer, 1995]. While the cyclones do have increased moisture available for growth, they also experience an effective reduction in the dry baroclinicity due to the increased poleward and upward moisture transport [O'Gorman and Schneider, 2008; Schneider et al., 2010].

In current model projections the balance of evidence suggests that the latter of these two mechanisms dominates. There have been conflicting results in past studies of changing cyclone intensity; largely, it seems due to the contamination of pressure-based cyclone measures by large-scale flow features [Ulbrich et al., 2009; Chang, 2014]. There is an emerging consensus of generally weak or negligible changes in cyclone intensity, despite an increase in the precipitation in the storm tracks [Bengtsson et al., 2009; Zappa et al., 2013]. This is consistent with the energetic argument; effectively, the balance of cyclone-driving factors shifts from dry to moist with minimal resulting change in cyclone intensity. However, confidence in these projections is limited by the skill of climate models in representing moist effects, due to deficiencies in resolution and physical parameterizations [Willison et al., 2013]. This motivates the question posed in this paper: can recent reanalyses provide a guide to how cyclone intensity changes as temperature rises? Warming on the global scale has been evident over recent decades, and many studies have tested for concurrent trends 
in observational storm track metrics [e.g., Wang et al., 2013]. Some consistent regional features have been identified, such as multidecadal changes in the Atlantic storm track, but these generally seem related to variations in atmospheric circulation patterns rather than the warming trend [Feser et al., 2014].

In addition to the global-scale warming, regional patterns of natural variability have shaped the recent temperature evolution. In particular, Atlantic Multidecadal Variability (AMV) describes basin-wide changes in the temperature of the North Atlantic, often characterized by relatively rapid changes between cold and warm periods which typically last a few decades [e.g., Robson et al., 2012]. Sutton and Dong [2012] compared two recent warm AMV periods to the intervening cold period, finding clear shifts in precipitation and temperature patterns across Europe. In this paper the warm AMV periods (1948-1960 and 1997-2011) are compared to the cold period (1979-1993) as analogues for future warming. This provides some observational evidence for how cyclone intensity is affected by an increase in temperature and moisture content, albeit in reanalysis rather than pure observational data.

\section{Methods}

The 6-hourly data with a T62 ( 209 km grid) resolution for the 64 year period 1948-2011 from the National Centers for Environmental Prediction-National Center for Atmospheric Research (NCEP-NCAR) reanalysis-1 [Kalnay et al., 1996], and the 6-hourly ERA-Interim data with a higher resolution of T255 ( $80 \mathrm{~km}$ grid) for the later 33 year period 1979-2011 from the European Centre for Medium-Range Weather Forecasts (ECMWF) [Dee et al., 2011] are used as the primary data for this study. Results are contrasted with 44 year (1963-2006) simulations of the ECMWF model forced with the observed sea surface temperature (SST) evolution from Project Athena [Jung et al., 2012], using one simulation of both low and high resolutions of T159 ( 128 km grid) and T1279 ( 16 km grid). This comparison allows an assessment of the potential sensitivity of cyclone intensity to atmospheric resolution.

Cyclones are tracked using the Hodges tracking algorithm applied as in Hoskins and Hodges [2002]. This uses the relative vorticity field at $850 \mathrm{hPa}$ filtered to $\mathrm{T} 42$ resolution, to reduce the noise in this field and to enable the identification of cyclones at a common resolution. Cyclones are identified as the off-grid vorticity maxima (interpolated between grid cells). The large-scale background field is also removed as described in Hoskins and Hodges [2002]. Following the tracking the tracks are filtered to retain only those that last longer than 2 days and travel further than $1000 \mathrm{~km}$, so focusing on the mobile synoptic cyclones. Other intensity measures are added to the tracks for other variables using the methods described in Bengtsson et al. [2009]. The additional intensity measures are the full resolution vorticity, mean sea level pressure (MSLP) minima, winds at $850 \mathrm{hPa}$ and $925 \mathrm{hPa}$, vertical velocity (omega), and precipitation. The added measures entail determining the maximum of the full resolution vorticity and winds within $6^{\circ}$ and $7^{\circ}$, respectively, of the cyclone center using a direct search of the grid point values falling within these radii and the minimum within $6^{\circ}$ for omega. For MSLP the true minima are determined using B-spline interpolation and a steepest descent minimization within a radius of $6^{\circ}$ of the cyclone center, and for precipitation the area average within $6^{\circ}$ of the center is computed. This study analyzes all these intensity measures including the tracked T42 vorticity. The regions focused on are the North Atlantic basin $\left(30^{\circ} \mathrm{N}-70^{\circ} \mathrm{N}, 285^{\circ} \mathrm{E}-360^{\circ} \mathrm{E}\right)$ and the North Pacific basin $\left(30^{\circ} \mathrm{N}-60^{\circ} \mathrm{N}, 140^{\circ} \mathrm{E}-230^{\circ} \mathrm{E}\right)$. The target storms are those whose maximum $\mathrm{T} 42$ vorticity occurs in the considered region. During the lifetime of each storm both maximum and mean values of each intensity measure are recorded. If these regions are varied, for example, by extending to higher and lower latitudes, there are some changes to the results for individual data set/season combinations, but no change to the robust general results.

A nonparametric Monte Carlo significance testing method with a two-sided 5\% significance level is employed in this study to test whether the average intensity differences between warm and cold periods in the reanalysis and simulation data are due to random sampling of years. To obtain a random sample, the years in warm and cold periods, say $m$ warm years and $n$ cold years, are combined into a set of $m+n$ years. The years are then randomly shuffled and separated into two sets of $m$ and $n$ years. The calculated average intensity difference between the two sets is stored as one sample element for comparison with the real difference. The sample size used in this paper is 10,000 for all intensity measures. 

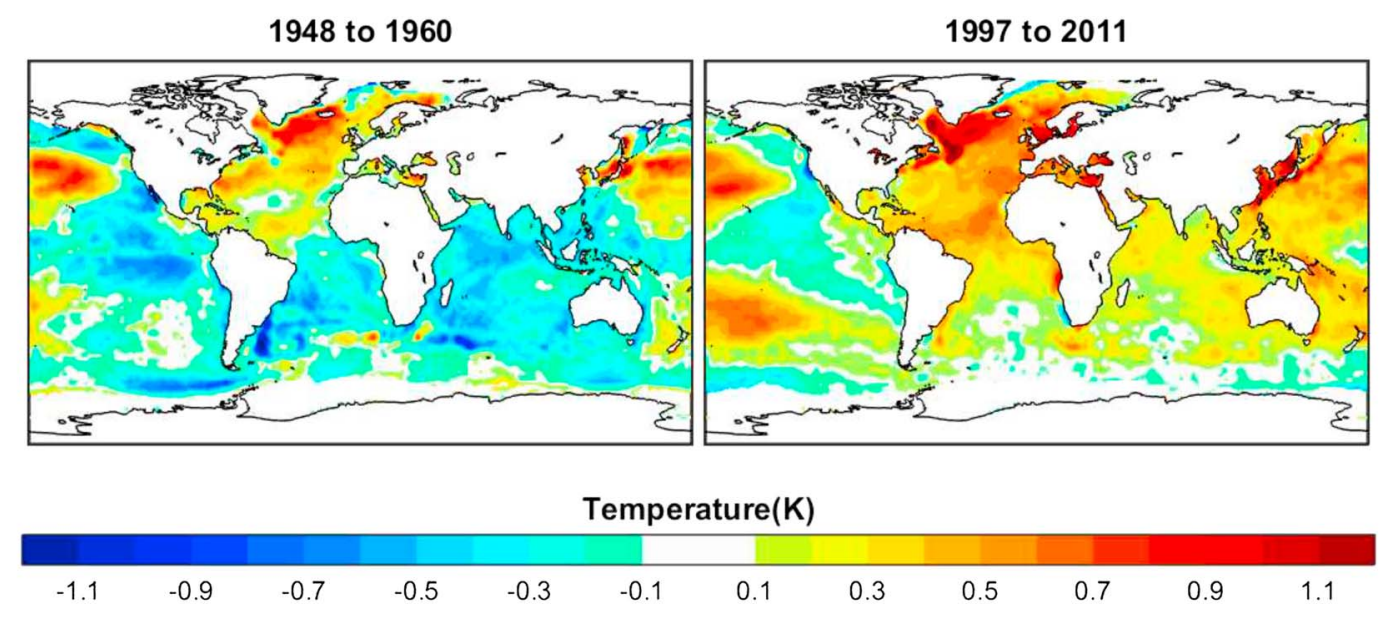

Figure 1. Annual SST change based on Hadley Centre Global Sea Ice and SST (HadISST) data in the two warm periods 1948-1963 and 1997-2011, compared to the cold period 1979-1993.

\section{Recent Climate Changes}

Increases in average SST in the warmer periods (1948-1960 and 1997-2011) compared to the 1979-1993 base period have been detected in both ocean basins. In the North Atlantic, an overall warming appears for all seasons in both warm periods in contrast to the cold period, which results in a significant increase in annual mean SST (Figure 1). In the North Pacific, comparing the early warm period with the cold period, the SST change is characterized by regional warming and cooling, with a warming in both central and western parts and relatively weak cooling along the American western coast, while the later warm period only shows an SST increase in the central North Pacific. Although the focus in this paper is on the North Atlantic, the later warm period in particular also captures a Pacific warming signal, so some reference will also be made to Pacific cyclones.

Figure 2 shows the vertical structure of North Atlantic temperature and specific humidity differences between the warm and cold periods. Both warm periods exhibit considerable warming in the middle- to high-latitude lower troposphere, as compared to the intervening cold period. The later warm period in particular is a good analogue of future warming in the lower troposphere, while the earlier period exhibits cold temperatures at lower latitudes and so is less similar to the structure seen in future projections. However, both warm periods are characterized by an increase in specific humidity in the lower troposphere, from the (sub)tropics to high latitudes, and so provide a possible guide to how cyclones may change with increased moisture.

For comparison, the multimodel ensemble average of projected surface air temperature change (compared to 1986-2005) from Collins et al. [2013] indicates about $1-1.5^{\circ} \mathrm{C}$ rise in the North Atlantic in 2046-2065, and about $1.5-2^{\circ} \mathrm{C}$ rise in $2081-2100$. Hence, the recent Atlantic warming has roughly the same magnitude as the 2046-2065 projection.

Although the warm periods feature increased temperature and specific humidity, they are still only partial analogues of projected future changes. As evidence for this, Figure 3 shows the changes in lower tropospheric transient sensible heat and moisture fluxes between the recent warm and cold periods. The sensible heat transport $v^{\prime} T^{\prime}$ decreases during warm periods, as expected to compensate the implied increase in ocean poleward heat transport [Shaffrey and Sutton, 2006]. However, the moisture flux $v^{\prime} q^{\prime}$ also decreases in the warm period. Correlated changes in sensible and latent heat fluxes such as these are a feature of the natural variability of the coupled system, likely driven by variations in ocean circulation [Trenberth and Stepaniak, 2003; Vallis and Farneti, 2009; Farneti and Vallis, 2013]. In contrast, the response to external forcing is typically driven by changes in the latent heat fluxes with the sensible heat fluxes compensating [Magnusdottir and Saravanan, 1999; Caballero and Langen, 2005; Held and Soden, 2006; Hwang et al., 2011; Schneider et al., 2010]. A related factor is the contrasting Atlantic meridional SST gradients, which decreased in the recent warm periods (Figure 1) but are projected to increase in the future [Woollings et al., 2012]. 

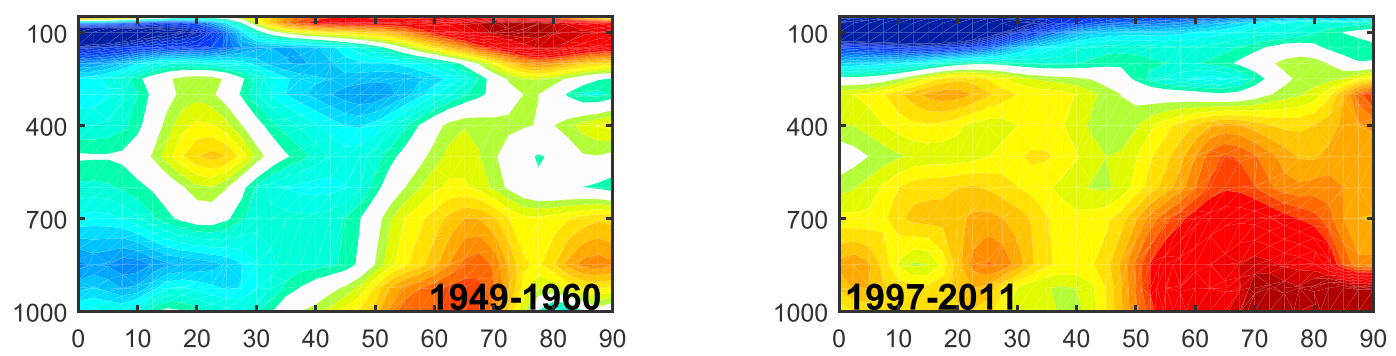

\section{Temperature (K)}

$\begin{array}{llllllllllllllll}-1.5 & -1.3 & -1.1 & -0.9 & -0.7 & -0.5 & -0.3 & -0.1 & 0.1 & 0.3 & 0.5 & 0.7 & 0.9 & 1.1 & 1.3 & 1.5\end{array}$
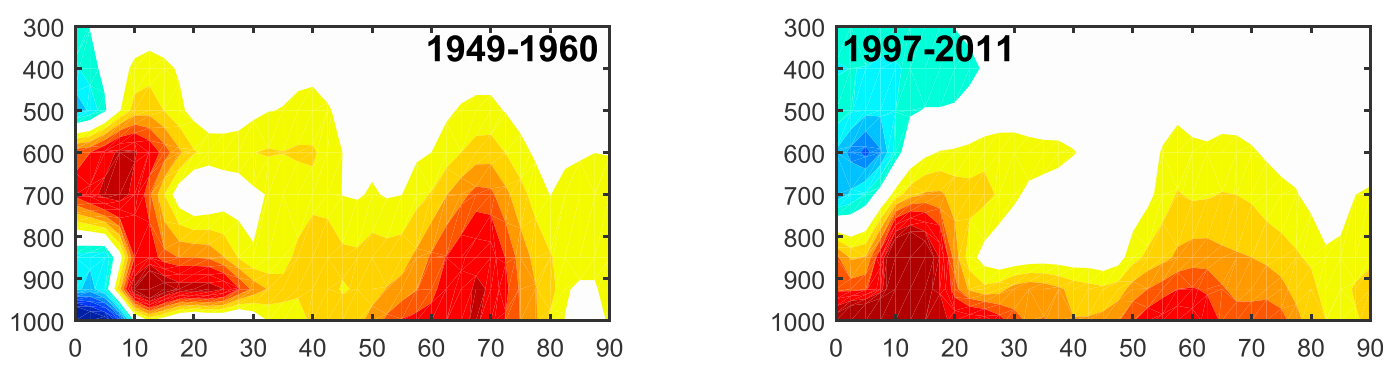

Specific Humidity ( $/ \mathbf{k g})$

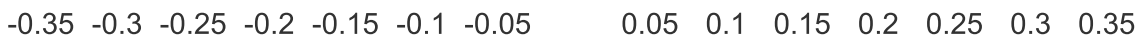

Figure 2. North Atlantic $285^{\circ} \mathrm{E}-360^{\circ} \mathrm{E}$ latitude-by-pressure (top) air temperature change and (bottom) specific humidity change for 1949-1960 and 1997-2011 compared to 1979-1993. Data from the NCEP-NCAR reanalysis.

However, the similarity of Atlantic and Pacific results presented below suggests this is not a major factor, at least for cyclone intensity at annual resolution.

\section{Changes in Cyclone Intensity}

To summarize the change in cyclones between warm and cold periods, Figure 4 shows the distributions of two intensity measures: the maximum precipitation and the maximum unsmoothed vorticity field, both for

\section{vT(left) and vq(right) at $850 \mathrm{mb} 1997$ to 2010 minus 1980 to 1993}
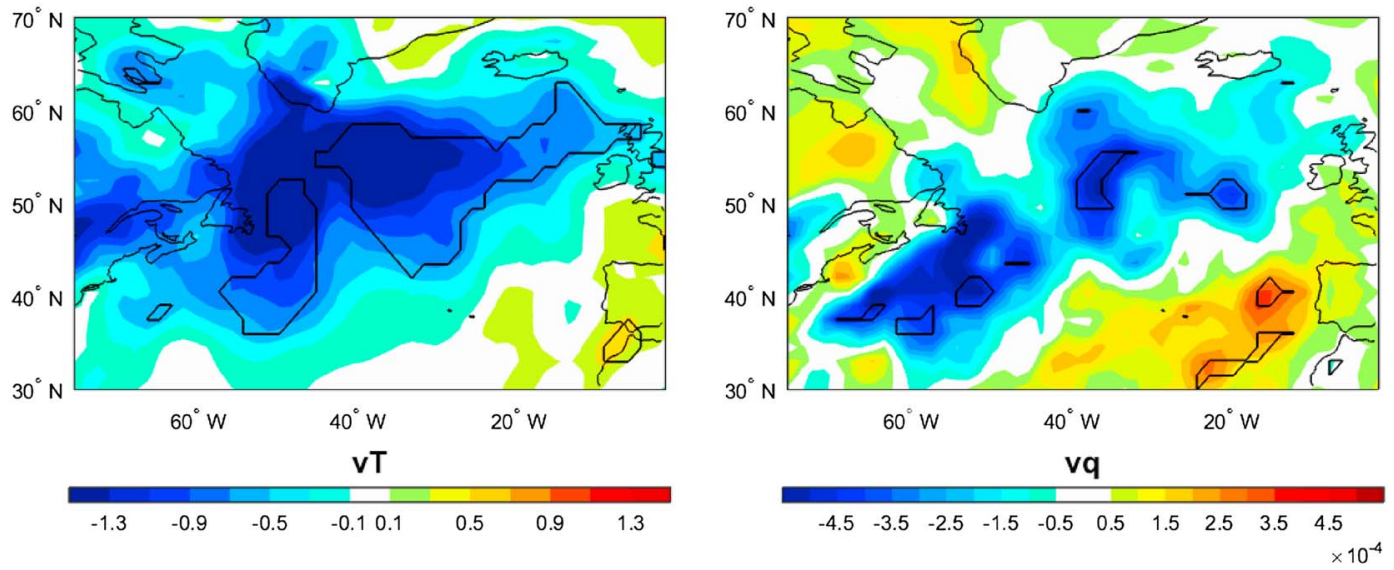

Figure 3. North Atlantic annual mean transient flux $v^{\prime} T^{\prime}$ (in $\mathrm{m} \mathrm{Ks}^{-1}$ ) and $v^{\prime} q^{\prime}$ (in m g kg-1 $\mathrm{s}^{-1}$ ) changes at $850 \mathrm{mb}$ between the later warm period and the cold period. The data are derived from ERA-Interim and were daily meaned and then Lanczos filtered to retain only variations on the 2-6 day timescale. A two-sided $t$ test is used to test whether the change at each grid point between two periods are significant at the $5 \%$ level. The thick black contours surround the area where the change is significant. 

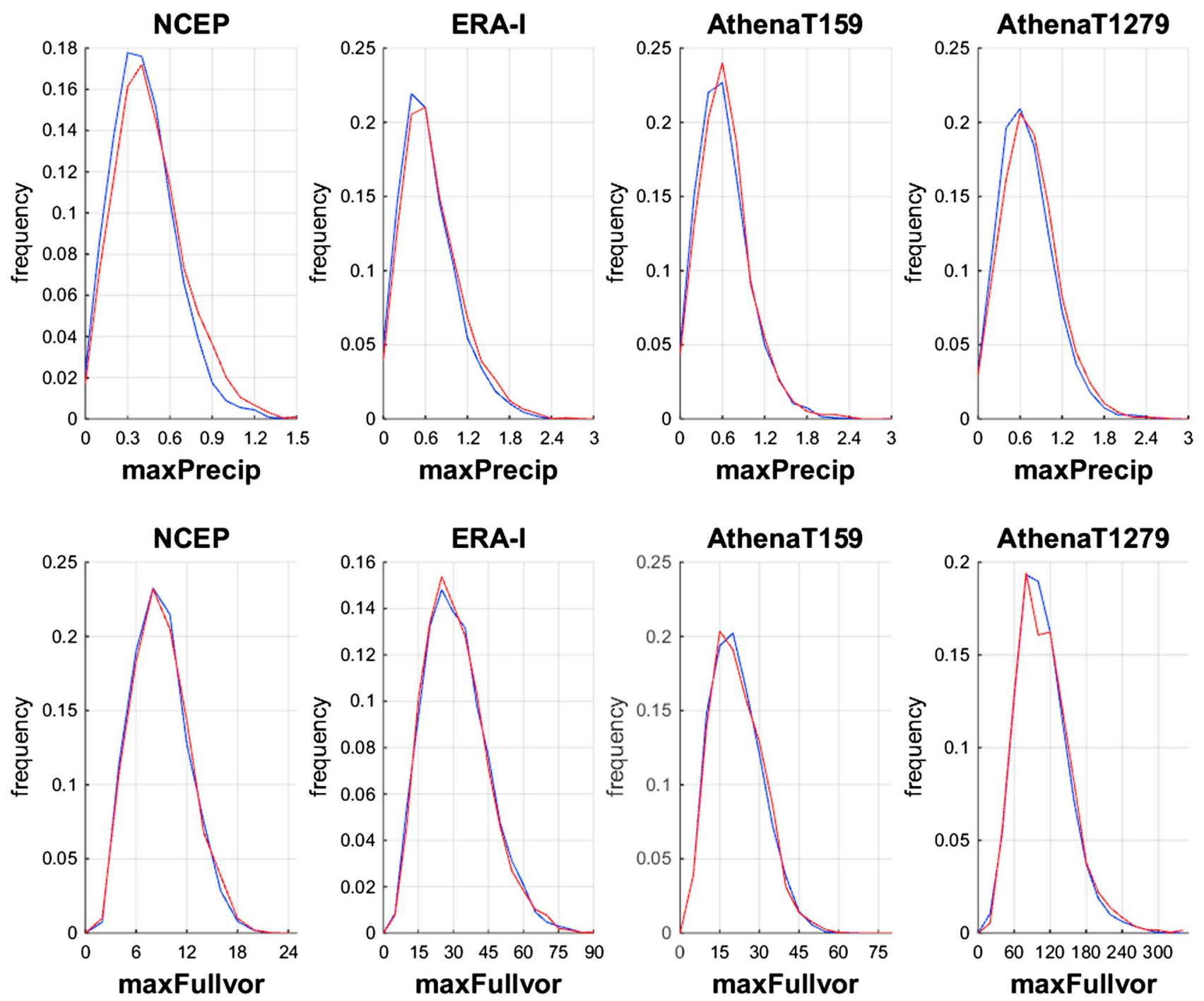

Figure 4. Examples of annual distributions for maximum precipitation and maximum full vorticity over North Atlantic $30^{\circ} \mathrm{N}-70^{\circ} \mathrm{N} 285^{\circ} \mathrm{E}-360^{\circ} \mathrm{E}$, with red lines denoting the later warm period 1997-2011 and blue lines denoting the cold period 1979-1993. The unit for maximum precipitation is mm/h and the unit for maximum full resolution vorticity is $\times 10^{-5} \mathrm{~s}^{-1}$.

North Atlantic cyclones. These are shown for all four data sets, comparing the recent warm period to the cold period, and are supported by a seasonal breakdown of the significance of the mean changes in Table 1. Complete tables of all intensity measures as well as cyclone counts and lifetimes, including for North Pacific cyclones, are given in the supporting information.

The most consistent result from the reanalysis data is generally increased cyclone-associated precipitation in warm periods, which is also supported by the T1279 resolution Athena simulation. This is evident from a shift in the distributions shown in Figure 4 and the significance values in Table 1. In the reanalyses in particular, similar and significant changes are seen in most or all seasons, which add confidence to this result. In several cases there are also warm period increases in precipitation in Pacific storms (supporting information), although the changes are generally more significant and consistent in the North Atlantic. This is consistent with the relatively larger increase in temperature and specific humidity in the North Atlantic but again adds confidence to the generality of the result. An intriguing counterexample is the T159 Athena simulation which shows a clear warm period increase in precipitation in the Pacific but not the Atlantic.

In contrast, the vorticity distributions in Figure 4 show no clear difference between the warm and cold periods. According to the significance tests in Table 1, both NCEP and Athena T1279 do exhibit a significant increase in vorticity in the warm period when annual data are used. However, the results in individual 
Table 1. $P$ Values of Significance Tests Carried Out on Selected Intensity Measures Over the North Atlantic $30^{\circ} \mathrm{N}-70^{\circ} \mathrm{N}$ $285^{\circ} \mathrm{E}-360^{\circ} \mathrm{E}$ for All Seasons ${ }^{\mathrm{a}}$

\begin{tabular}{lccccc}
$p$ value & DJF & MAM & JJA & SON & Annual \\
\hline Max Precip (NCEP) & $\mathbf{2 . 1 7} \%$ & $\mathbf{0 . 1 3} \%$ & $\mathbf{0 . 0 2} \%$ & $\mathbf{0 . 0 1} \%$ & $\mathbf{0 . 0 1} \%$ \\
Max Precip (ERA-I) & $\mathbf{1 . 0 9} \%$ & $\mathbf{1 . 3 5} \%$ & $11.61 \%$ & $\mathbf{0 . 2 5} \%$ & $\mathbf{0 . 0 1} \%$ \\
Max Precip (Athena T159) & $9.62 \%$ & $27.89 \%$ & $27.54 \%$ & $6.34 \%$ & $4.99 \%$ \\
Max Precip (Athena T1279) & $7.02 \%$ & $\mathbf{1 . 4 1} \%$ & $6.75 \%$ & $\mathbf{0 . 0 1} \%$ & $\mathbf{0 . 0 1} \%$ \\
Max Fullvor (NCEP) & $22.71 \%$ & $\mathbf{1 . 9 1} \%$ & $-38.08 \%$ & $10.53 \%$ & $\mathbf{2 . 0 3} \%$ \\
Max Fullvor (ERA-I) & $-6.61 \%$ & $27.14 \%$ & $-11.96 \%$ & $24.93 \%$ & $-27.85 \%$ \\
Max Fullvor (Athena T159) & $22.72 \%$ & $27.62 \%$ & $14.92 \%$ & $38.92 \%$ & $21.48 \%$ \\
Max Fullvor (Athena T1279) & $36.74 \%$ & $6.14 \%$ & $\mathbf{1 . 5 2} \%$ & $15.95 \%$ & $\mathbf{1 . 7 2} \%$ \\
\hline
\end{tabular}

${ }^{a}$ The warm period used is 1997-2011, and the change is based on the cold period 1979-1993. A minus sign means a decrease in the average maximum intensity. Values which are significant at the $95 \%$ level in a two-sided test are marked in bold. DJF: December-February; MAM: March-May; JJA: June-August; SON: September-November.

seasons are not clearly in agreement and have little significance. This increase is not seen in ERA-Interim or in the earlier warm period in NCEP so is not a robust result. Changes in other intensity measures such as wind speeds vary significantly depending on data set. Few of these changes are significant in more than one season and across different data sets. One interesting contrast between the reanalyses is a clear increase in (absolute) omega in both basins in NCEP, while ERA-I does not show any increase in all seasons.

The early warm period in NCEP shows general decreases in most intensity measures in both basins, as compared to the cold period. These changes are likely artifacts of the reanalysis induced by lack of observations in early years [Harnik and Chang, 2003; Bengtsson et al., 2004]. There is increased precipitation in the early warm period, in agreement with the later changes; however, this may also be influenced by biases in the reanalysis.

Intriguingly, significant differences between the low- and high-resolution Athena simulations are apparent. At T159 resolution there is no change in all intensity measures in both basins at the $5 \%$ significance level, with one exception of increasing Pacific precipitation. However, at T1279 resolution some significant increases in T42 vorticity, full vorticity (maximum only), and $925 \mathrm{hPa}$ wind speed are seen in the Atlantic basin but not in the Pacific. Higher resolution also shows increasing precipitation in both basins and an increase in intensity as measured by MSLP in the Pacific basin only. Since the MSLP is an absolute measure, this latter change may reflect a change in mean atmospheric circulation in the high-resolution simulation [Chang, 2014]. Further investigation, for example, with larger data sets, would be desirable to establish the robustness of these changes, but they do suggest that different results could be obtained when using higher resolution, especially for these resolution-sensitive intensity measures. Resolution dependence could potentially have an impact on cyclone intensity in reanalysis data as well [Hodges et al., 2011; Tilinina et al., 2013].

Changes in the average numbers of cyclones per year have also been recorded. A significant decrease of cyclone numbers in both summer and on the annual scale are shown in the T1279 resolution Athena data, but no similar results in other data sets could support this change. No significant changes in cyclone lifetimes have been found.

\section{Discussion}

In this paper we consider recent climate changes, largely associated with AMV, as an analogue for projected future warming. The main conclusion is that current reanalysis data support the emerging consensus of climate projection studies, in that an increase in temperature and hence moisture in the atmosphere leads to an increase in the precipitation associated with cyclones, but no robust change in the intensity of cyclones as measured by quantities such as vorticity or wind speed. This is consistent with the theory that increased moisture enhances the efficiency of poleward heat transport by the storm track, rather than invigorating cyclones through latent heat release. The implication is that current climate models are not missing dominant processes involved in the storm track response to climate change, in agreement with Booth et al. [2013]. 
AMV is clearly only a partial analogue for future change, however. For example, the transient atmospheric heat and moisture fluxes covary in AMV while they oppose each other in future projections. Similarly, the meridional temperature gradient in the North Atlantic weakens during AMV but strengthens in the projections, and so the cyclone changes identified here may arise from dynamical, rather than thermodynamical effects [Gastineau and Frankignoul, 2012; Nissen et al., 2013]. To account for this, we consider the robustness of changes across all seasons, since there is no evidence that the effect of moisture fuelling on cyclones will vary with season. In contrast, AMV has been linked with physically quite different seasonal changes: a shift of the storm track in summer [Dong et al., 2013] and a change in strength in winter [Woollings et al., 2014]. Our main result of an increase in cyclone-associated precipitation is robust across all seasons, with no associated robust increase in other intensity measures.

There are other caveats to our conclusion. One of these is highlighted by the analysis of the Athena simulations, which are driven by the observed SST variations. These do show changes at high resolution which are not seen at low resolution, in particular some significant increases in vorticity and decreases in cyclone numbers in the recent warm period. This supports the results of Willison et al. [2013] that the response of cyclones to moisture increases may be different at high resolution. In the reanalyses used here the synoptic-scale flow is strongly constrained by observations, but they are nonetheless blended with models and hence sensitive to parameterizations and data assimilation, for example. It remains possible that future generations of (higher-resolution) reanalyses may behave differently.

Another concern regards the accuracy of the precipitation, which is a forecast variable in reanalyses. Analysis of the Eulerian mean precipitation differences between the periods does not show agreement between reanalyses and other precipitation data sets, such as GPCP (not shown). However, this may arise from inhomogeneities in the other data sets as well as problems with the reanalyses [Dee et al., 2011]. Artificial trends in the reanalysis circulation fields may be of importance here, as in Bengtsson et al. [2004], although our focus on the satellite era minimizes this problem. Finally, only one cyclone tracking method is used here, although Ulbrich et al. [2013] find that intense cyclones are generally identified similarly by different methods.

Our analysis provides an area-integrated view of cyclone changes across the storm tracks. The recent studies of Dacre and Gray [2013] and Ludwig et al. [2014] suggest that particular types of cyclones may be especially sensitive to increases in latent heat release, and this is not necessarily inconsistent with the results presented here.

Acknowledgments

We are grateful to the NOAA/ESRL Physical Sciences Division, Boulder, Colorado, NCEP-NCAR, and the ECMWF for providing the reanalysis data and to ECMWF and Project Athena for providing the model data. These data are available from http://www.esrl. noaa.gov/psd/data/gridded/data.ncep. reanalysis.html, http://apps.ecmwf.int/ datasets/, and http://www.wxmaps. org/athena/home/, respectively. Giacomo Masato was partly supported by the Joint UK DECC/Defra Met Office Hadley Centre Climate Programme (GA01101). We thank the UK Met Office and the National Centre for Atmospheric Science for additional financial support and James Booth and an anonymous reviewer for helpful comments.

The Editor thanks two anonymous reviewers for their assistance in evaluating this paper.

\section{References}

Bengtsson, L., S. Hagemann, and K. I. Hodges (2004), Can climate trends be calculated from reanalysis data?, J. Geophys. Res., 109, D11111, doi:10.1029/2004JD004536.

Bengtsson, L., K. I. Hodges, and N. Keenlyside (2009), Will extratropical storms intensify in a warmer climate?, J. Clim., 22, 2276-2301, doi:10.1175/2008JCLI2678.1.

Boer, G. J. (1995), Some dynamical consequences of greenhouse gas warming, Atmos.-Ocean, 33(4), 731-751.

Booth, J. F., S. Wang, and L. Polvani (2013), Midlatitude storms in a moister world: Lessons from idealized baroclinic life cycle experiments, Clim. Dyn., 41(3-4), 787-802.

Caballero, R., and P. L. Langen (2005), The dynamic range of poleward energy transport in an atmospheric general circulation model, Geophys. Res. Lett., 32, L02705, doi:10.1029/2004GL021581.

Chang, E. K. (2014), Impacts of background field removal on CMIP5 projected changes in Pacific winter cyclone activity, J. Geophys. Res. Atmos., 119, 4626-4639, doi:10.1002/2013JD020746.

Collins, M., et al. (2013), Long-term climate change: Projections, commitments and irreversibility, in Climate Change 2013: The Physical Science Basis. Contribution of Working Group I to the Fifth Assessment Report of the Intergovernmental Panel on Climate Change, edited by T. F. Stocker et al., pp. 1029-1136, Cambridge Univ. Press, Cambridge, U. K., and New York.

Dacre, H. F., and S. L. Gray (2013), Quantifying the climatological relationship between extratropical cyclone intensity and atmospheric precursors, Geophys. Res. Lett., 40, 2322-2327, doi:10.1002/grl.50105.

Dee, D., et al. (2011), The ERA-Interim reanalysis: Configuration and performance of the data assimilation system, Q. J. R. Meteorol. Soc., 137(656), 553-597.

Dong, B., R. T. Sutton, T. Woollings, and K. Hodges (2013), Variability of the North Atlantic summer storm track: Mechanisms and impacts on European climate, Environ. Res. Lett., 8(3), 034,037, doi:10.1088/1748-9326/8/3/034037.

Farneti, R., and G. K. Vallis (2013), Meridional energy transport in the coupled atmosphere-ocean system: Compensation and partitioning, J. Clim., 26(18), 7151-7166.

Feser, F., M. Barcikowska, O. Krueger, F. Schenk, R. Weisse, and L. Xia (2014), Storminess over the North Atlantic and northwestern Europe: A review, Q. J. R. Meteorol. Soc., doi:10.1002/qj.2364.

Gastineau, G., and C. Frankignoul (2012), Cold-season atmospheric response to the natural variability of the Atlantic meridional overturning circulation, Clim. Dyn., 39, 37-57, doi:10.1007/s00382-011-1109-y.

Gutowski, W. J., L. E. Branscome, and D. A. Stewart (1992), Life cycles of moist baroclinic eddies, J. Atmos. Sci., 49, $306-319$.

Harnik, N., and E. K. M. Chang (2003), Storm track variations as seen in radiosonde observations and reanalysis data, J. Clim., 16, 480-495. 
Harvey, B., L. Shaffrey, and T. Woollings (2013), Equator-to-pole temperature differences and the extra-tropical storm track responses of the CMIP5 climate models, Clim. Dyn., 43, 1171-1182, doi:10.1007/s00382-013-1883-9.

Held, I. M., and B. J. Soden (2006), Robust responses of the hydrological cycle to global warming, J. Clim., 19(21), 5686-5699.

Hodges, K., R. Lee, and L. Bengtsson (2011), A comparison of extratropical cyclones in recent reanalyses ERA-Interim, NASA MERRA, NCEP CFSR, and JRA-25, J. Clim., 24(18), 4888-4906.

Hoskins, B. J., and K. I. Hodges (2002), New perspectives on the Northern Hemisphere winter storm tracks, J. Atmos. Sci., 59, $1041-1061$. Hwang, Y.-T., and D. M. Frierson (2010), Increasing atmospheric poleward energy transport with global warming, Geophys. Res. Lett., 37, L24807, doi:10.1029/2010GL045440.

Hwang, Y.-T., D. M. Frierson, B. J. Soden, and I. M. Held (2011), CORRIGENDUM: Corrigendum for Held and Soden (2006), J. Clim., 24(5), 1559-1560.

Jung, T., et al. (2012), High-resolution global climate simulations with the ECMWF model in Project Athena: Experimental design, model climate, and seasonal forecast skill, J. Clim., 25(9), 3155-3172.

Kalnay, E., et al. (1996), The NCEP/NCAR 40-year reanalysis project, Bull. Am. Meteor. Soc., 77, 437-471.

Ludwig, P., J. G. Pinto, M. Reyers, and S. L. Gray (2014), The role of anomalous SST and surface fluxes over the southeastern North Atlantic in the explosive development of windstorm Xynthia, Q. J. R. Meteorol. Soc., 140, 1729-1741.

Magnusdottir, G., and R. Saravanan (1999), The response of atmospheric heat transport to zonally averaged SST trends, Tellus A, 51(5), $815-832$.

Manabe, S., and K. Bryan (1985), CO2-induced change in a coupled ocean-atmosphere model and its paleoclimatic implications, J. Geophys. Res., 90(C6), 11,689-11,707.

Nissen, K. M., U. Ulbrich, G. C. Leckebusch, and I. Kuhnel (2013), Decadal windstorm activity in the North Atlantic-European sector and its relationship to the meridional overturning circulation in an ensemble of simulations with a coupled climate model, Clim. Dyn., 43, 1545-1555, doi:10.1007/s00382-013-1975-6.

O'Gorman, P. A., and T. Schneider (2008), Energy of midlatitude transient eddies in idealized simulations of changed climates, J. Clim., 21(22), 5797-5806.

Robson, J., R. Sutton, K. Lohmann, D. Smith, and M. D. Palmer (2012), Causes of the rapid warming of the North Atlantic Ocean in the mid-1990s, J. Clim., 25(12), 4116-4134.

Schneider, T., P. A. O'Gorman, and X. J. Levine (2010), Water vapor and the dynamics of climate changes, Rev. Geophys., 48, RG3001, doi:10.1029/2009RG000302.

Shaffrey, L., and R. Sutton (2006), Bjerknes compensation and the decadal variability of the energy transports in a coupled climate model, J. Clim., 19, 1167-1181.

Sutton, R. T., and B. Dong (2012), Atlantic Ocean influence on a shift in European climate in the 1990s, Nat. Geosci., 5(11), 788-792.

Tilinina, N., S. K. Gulev, I. Rudeva, and P. Koltermann (2013), Comparing cyclone life cycle characteristics and their interannual variability in different reanalyses, J. Clim., 26(17), 6419-6438.

Trenberth, K. E., and D. P. Stepaniak (2003), Covariability of components of poleward atmospheric energy transports on seasonal and interannual timescales, J. Clim., 16(22), 3691-3705.

Ulbrich, U., G. C. Leckebusch, and J. G. Pinto (2009), Extra-tropical cyclones in the present and future climate: A review, Theor. Appl. Climatol., 96, 117-131, doi:10.1007/s00704-008-0083-8.

Ulbrich, U., et al. (2013), Are greenhouse gas signals of northern hemisphere winter extra-tropical cyclone activity dependent on the identification and tracking algorithm?, Meteorol. Z., 22(1), 61-68.

Vallis, G. K., and R. Farneti (2009), Meridional energy transport in the coupled atmosphere-ocean system: Scaling and numerical experiments, Q. J. R. Meteorol. Soc., 135(644), 1643-1660.

Wang, X. L., Y. Feng, G. Compo, V. Swail, F. Zwiers, R. Allan, and P. Sardeshmukh (2013), Trends and low frequency variability of extra-tropical cyclone activity in the ensemble of twentieth century reanalysis, Clim. Dyn., 40(11-12), 2775-2800.

Willison, J., W. A. Robinson, and G. M. Lackmann (2013), The importance of resolving mesoscale latent heating in the North Atlantic storm track, J. Atmos. Sci., 70(7), 2234-2250.

Woollings, T., J. M. Gregory, J. G. Pinto, M. Reyers, and D. J. Brayshaw (2012), Response of the North Atlantic storm track to climate change shaped by ocean-atmosphere coupling, Nat. Geosci., 5, 313-317, doi:10.1038/ngeo1438.

Woollings, T., C. Franzke, D. Hodson, B. Dong, E. Barnes, C. Raible, and J. Pinto (2014), Contrasting interannual and multidecadal NAO variability, Clim. Dyn., doi:10.1007/s00382-014-2237-y.

Zappa, G., L. C. Shaffrey, K. I. Hodges, P. G. Sansom, and D. B. Stephenson (2013), A multimodel assessment of future projections of North Atlantic and European extratropical cyclones in the CMIP5 climate models, J. Clim., 26(16), 5846-5862. 